\title{
Determinants of Poor Quality of Life Among Adults Living with HIV and Enrolled in Highly Active Anti-Retroviral Therapy at Public Health Facilities of Arba Minch Town Administration in Southern Ethiopia
}

This article was published in the following Dove Press journal:

HIVIAIDS - Research and Palliative Care

\begin{abstract}
Abel Legesse Tesemma' Meseret Girma Abate ${ }^{2}$ Zeleke Hailemariam Abebo iD ${ }^{2}$ Wubshet Estifanos Madebo (iD) ${ }^{3}$

'Bona General Hospital, Hawassa, Sidama, Ethiopia; ${ }^{2}$ Department of Public Health, College of Medicine and Health Science, Arba Minch University, Arba Minch, Ethiopia; ${ }^{3}$ Department of Nursing, College of Medicine and Health Science, Arba Minch University, Arba Minch, Ethiopia
\end{abstract}

Correspondence: Zeleke Hailemariam Abebo

Department of Public Health, College of Medicine and Health Science, Arba Minch University, P.O. Box 21, Arba Minch, Ethiopia Tel +251 912471521

Email zelehyle@gmail.com
Background: The human immunodeficiency virus (HIV) continues to be a major global public health problem with more than 35 million people worldwide infected so far. Evidence shows that HIV has been compromising the quality of life of people living with HIV (PLWH) even in this era of highly active anti-retroviral therapy (HAART). There has been little research into the quality of life of PLWH receiving HAART in Ethiopia.

Purpose: The aim of this study was to assess the quality of life among PLWH attending anti-retroviral therapy at public health facilities of Arba Minch town, Southern Ethiopia, in 2019.

Patients and methods: We conducted a cross-sectional study design on 391 randomly selected PLWH who were attending HAART. We used a systematic random sampling technique to select participants in public health facilities of Arba Minch town from February 16 to April 26, 2019. The interviewers administered a structured questionnaire consisting of the WHOQOL-HIV BREF tool to measure the quality of life. Socio-demographic variables of study participants were collected, together with variables related to their clinical status extracted from their clinical records. Percentage mean scores were calculated and the mean of percentage mean scores was taken as the cutoff to categorize participants into two groups representing poor and good quality of life. Simple binary logistic regression and multivariable logistic regression analyses were used to determine significant variables. All variables with $p$-value $\leq 0.25$ in simple binary logistic regression were considered as eligible variables for multivariable logistic regression. Variables with p-value $\leq 0.05$ in multivariable logistic regression were considered as predictor variables.

Results: Out of the 391 enrolled adult PLWH, 184 of them (47.1\%) had poor of overall quality of life status, as estimated by the WHOQOL-HIV BREF tool. Good quality of life was positively associated with recent $\mathrm{CD} 4$ count greater than or equal to $500 \mathrm{cell} / \mathrm{mm}^{3}$ (AOR $=1.96,95 \% \mathrm{CI}$; 1.18-3.27), absence of depression ( $\mathrm{AOR}=10.59,95 \% \mathrm{CI}$; 6.16-18.21), normal body mass index $(\mathrm{AOR}=2.66,95 \% \mathrm{CI} ; 1.18-3.27)$, social support $(\mathrm{AOR}=6.18,95 \% \mathrm{CI} ; 3.56-10.75)$ and no perceived stigma (AOR=2.75, 95\% CI; 1.62-4.67).

Conclusion: Nearly half of the adult PLWH receiving HAART at Arba Minch town had poor quality of life. High CD4 count, lack of social support, depression, and perceived stigma were associated with poor quality of life of PLWH. PLWH should be encouraged to be part of structured social support systems, such as associations of people living with HIV and mother support groups, in order to improve their social and psychological health. The health system should give attention to counseling on chronic care adherence and nutritional support to improve the quality of life of PLWH receiving HAART.

Keywords: HAART.HIV/AIDS, CD4 count, depression, adherence, QOL, PLWH 


\section{Introduction}

Acquired immunodeficiency syndrome (AIDS) continues to be a major global public health issue, affecting more than 35 million lives so far, with severe impact on various facets of the human condition. The World Health Organization (WHO) estimates that around 36.9 million people are living with Human Immunodeficiency Virus (PLWH), and 1.8 million people out of those are newly infected. The major burden of the disease prevails in low and middle-income countries, with an estimated $66 \%$ of PLWH residing in sub-Saharan Africa (SSA). ${ }^{1}$ Ethiopia is one of the heavily affected SSA countries. The Ethiopian public health institute estimated in 2017 that there were 722,248 PLWH nationally, which constitutes $1.18 \%$ of the total population. ${ }^{2}$

Although highly active anti-retroviral therapy (HAART) and its widespread availability in many settings have reduced the mortality rate among PLWH, there are still challenges related to physical, psychological, and socio-cultural problems caused by many different factors including: symptoms of the virus, side effects of HAART, and opportunistic infections. ${ }^{3,4}$ In addition to the biological and physical impacts of the disease, many PLWH struggle with severe social problems such as stigma, poverty, depression, and substance abuse, which adversely affect their quality of life (QOL) and pose numerous barriers to the normal activities and interests of the patients. ${ }^{5}$

WHO defines quality of life as "an individuals' perception of their position in life in the context of the culture and value systems in which they live and in relation to their goals, expectations, standards and concerns." This definition incorporates each individual's satisfaction with their physical and psychological wellbeing, social relationships, environment and spiritual aspects of life. ${ }^{6}$ Measuring QOL using this definition is complex. However, a systematic review of quality of life measurements among PLWH suggests using the WHOQOL-HIV BREF questionnaire to distinguish QOL domains among study participants. ${ }^{7}$

Evidence shows that good QOL among PLWH in Asian countries ranges from $26 \%$ to $67 \% .^{8,9}$ Findings from Nigeria and Zambia revealed that a high proportion of patients had good or very good quality of life. ${ }^{10,11}$ The findings from Ghana and Burkina Faso indicated that good or very good quality of life status among PLWH were $79.75 \%$ and $82.4 \%$, respectively. ${ }^{12,13}$ In Ethiopia, a few studies have been conducted at Felege Hiwot Referral Hospital in the North of the country, and at Jimma town public health facilities, where good QOL was between $45 \%$ and $47 \% .{ }^{14,15}$ These studies indicate that sociodemographic characteristics of PLWH including age, gender, education, income/wealth index, employment status and disease-related variables, such as disease stage, opportunistic infection, CD4 count, and psychosocial characteristics, were associated with QOL. ${ }^{16-20}$ The numerous studies conducted across the globe on the QOL of PLWH distinguished psychological, social relationships, environment and spiritual aspects of life. ${ }^{6}$ However, measurements of QOL in different studies on PLWH show inconsistency, and the findings from high socio-economic countries do not accurately represent the situation in low socio-economic countries such as Ethiopia. In Ethiopia, not only are there limited studies, but there is also a scarcity of data that clearly shows the QOL and factors associated with QOL among PLWH. In addition, viral load is often neglected as a factor; in this study, we have included the association of viral load with the QOL of PLWH. Therefore, this study aimed to assess determinants of poor quality of life among people living with human immunodeficiency virus attending highly active antiretroviral therapy at public health facilities of Arba Minch town in Ethiopia.

\section{Methods}

\section{Study Area, Study Design and Population}

Arba Minch town is the capital city of Gamo zone administrations in Southern Ethiopia. There is one (1) general public hospital, serving as a referral hospital for patients from the surrounding districts, and there are two health centers (HC) in the town. Among the total of 2112 adult PLWH on ART in Arba Minch town, a total of 1699 attend for HIV care at Arba Minch General Hospital (AMGH), 395 at Sikella HC, and 18 at Shecha HC. All adult PLWH (aged greater than or equal to 15 years) enrolled in HAART at public health facilities of Arba Minch town were the source population. All adult PLWH (aged greater than or equal to 15 years) attending HAART during the study period at public health facilities of Arba Minch town were included as study population. Severely ill participants who were unable to respond and those participants with incomplete clinical charts were excluded. An institution-based cross-sectional study was conducted at the three 
public health facilities of Arba Minch town from February 26 to April 26, 2019.

\section{Sample Size Determination and Sampling Technique}

The sample size was calculated using a single population proportion formula incorporating the following assumptions: proportion of patients with poor quality of life was estimated as $56.4 \%,{ }^{14}$ with $95 \%$ certainty and $5 \%$ of maximum discrepancy between the upper and lower sample size. By adding $10 \%$ non-response rate, the total calculated sample size was 416 participants.

All public health facilities in the town were included in the study by proportionally allocating the sample size to each of the facilities based on their respective population size. The $\mathrm{K}$ value was determined by dividing the number of total PLWH on HAART to the total sample size $(\mathrm{N} / \mathrm{n})$ $=\mathrm{K}$ and lottery method was used to select the first participant among the first five. A systematic sampling technique with an interval of every $\mathrm{K}=5$ was used to recruit study subjects until the total required sample size of 416 participants was satisfied.

\section{Data Collection Procedure}

A pretested structured questionnaire comprising the short form of the WHOQOL-HIVBREF instrument, including socio-demographic characteristics, clinical, psychosocial and behavioral questions, was prepared and used to measure QOL among study participants. The WHOQOL-HIV BREF questionnaire contained 31 items in six (6) domains: physical health, psychological health, level of independence, social relationships, environment and religious/personal beliefs, as well as one item for quality of life and general health perception measurement. The clinical variables were: CD4 count, viral load, disease staging, current TB status, duration on HAART and nutritional status; these were collected from participants' medical records, whereas all other data we recollected by face-toface interview. Six Diploma nurses trained on HAART and two Bachelor of Science graduate nurses who had inservice training were recruited as data collectors and supervisors, respectively.

\section{Data Quality Control}

The data collection questionnaire was initially prepared in English and translated into Amharic and then re-translated back to English by language experts to check the consistency of the contents. Two-day training was conducted to build the capacity of data collectors and supervisors. Data completeness was checked every day. Data clearance and the coding of variables occurred during data entry. The data collection tool was pretested prior to the actual data collection period on $5 \%$ of patients attending HAART in Chencha primary hospital. Chencha primary hospital is one of the hospitals in Gamo-zone out of Arba Minch town, it was chosen due to the patients attending in this hospital were assumed to have similar socio-cultural situation. Rigorous supervision was done by both recruited supervisors and the investigators of this study.

\section{Data Processing and Analysis}

Data were entered into Epi-data version 4.4.2.1 then exported to SPSS version 23 for further analysis. Outliers were checked before running the analysis. Descriptive analysis was carried out and summarized by narration, tables and graphs. Any WHOQOL-HIV BREF questions that were written negatively were re-coded, so that all higher scores reflect a better quality of life. The mean score of items within each domain was calculated. The mean score was then multiplied by 4 in order to make domain scores comparable with the scores used in the WHOQOL instrument (WHOQOL-100). ${ }^{21}$ The overall percentage mean score for quality of life of PLWH in this study was calculated using the following formula: ${ }^{22}$

$$
\text { Percentages mean score }=\frac{\begin{array}{l}
\text { Actual score }- \text { potential } \\
\text { minimum score }
\end{array}}{\begin{array}{l}
\text { Potential maximum } \\
\text { score }- \text { potential } \\
\text { minimum score }
\end{array}}
$$

In the 5-point Likert-scale used to measure QOL in the items of each domain, values were labeled as 1 to represent minimum and 5 to represent maximum QOL. A participant's score that was above and (or) equal to the mean value was considered as indicating good quality of life. Conversely, a participant's score below the mean was considered as indicating poor quality of life. The Hosmer and Lemeshow statistics and deviance coefficient were used to check goodness of fit of the model. Multicollinearity and interaction effect were checked. Simple binary logistic regression analysis was done and all variables at $p$-value $<0.25$ were taken to multivariable binary logistic regression analysis. Statistical significance of variables at final model was declared at p-value $<0.05$ and $95 \%$ confidence level for adjusted odds ratio. 


\section{Ethical Considerations}

Ethical clearance was obtained from the Institutional Review Board of Arba Minch University, College of Medicine and Health Science. A support letter was received from the Department of Public Health, Arba Minch University. Permission was granted from the Chief Executive Officer of AMGH and the heads of the two HCs. Written informed consent was obtained from each participant whose age was greater than or equal 18 years, and for participants aged less than 18 years; written informed consent was taken from both parents and the participants themselves after informing the purpose, procedure of the study, the importance of their participation and the right to withdrawal at any time if they want. Privacy and confidentiality of the information of each respondent were kept properly. Personal identifiable information such as the participants' names were not recorded on the questionnaire.

\section{Operational Definitions \\ Overall Quality of Life}

Measured by using WHOQOL-HIV BIEF questionnaire that contains 31 questions distributed into 6 domains: physical, psychological, level of independence, social relationships, environmental domains and spirituality domains. In addition, there were two general health satisfaction and QOL perception rate items. The percentages mean score was calculated for each participant. Then, the mean score of percent mean scores was used as a cut-off to categorize the participants as poor (less than the mean score) and good (greater than or equal to the mean score). ${ }^{21,22}$

\section{Domains}

Mean scores of items within each domain were calculated. Mean scores were then multiplied by 4 in order to make domain scores comparable with the scores used in the WHO QOL (WHOQOL-100) Mean score. ${ }^{21}$

\section{Social Support}

A total score was obtained by computing responses to all items (ranging 19-95), with higher scores reflecting greater available support. In addition, individuals scoring above and equal to the mean social support score were categorized as "good social support" and those scoring below the mean were classified as "poor social support". 22

\section{Depression}

Depression was assessed using BDI-II (Beck Depression Inventory, Second Edition). It consists of 21 reverse coded questions scaled from 0 to 3 ; the lowest possible total score is zero and the highest possible total for the whole test is 63. BDI-II: $0-13$ points represented no depression and above 13 points represented depression. ${ }^{13}$

\section{Adherence}

Adherence was measured by patients' self-report of the number of HART doses missed during the past 1 month; the result was used to calculate percentage adherence. Participants were categorized as having good adherence if their scheduled dose was once per day and they missed less than or equal to 2 doses in the past 1 month, or if their scheduled dose was twice per day and they missed less than or equal to 3 doses in that period. Participants were considered to have poor adherence to their drug regimen if they exceeded these numbers of missed doses.

\section{Results}

\section{Socio-Demographic Characteristics}

Three hundred and ninety-one (391) study participants were interviewed in this study with a total response rate of $94 \%$. The majority of respondents were in the 35-44 age range (Table 1).

\section{Clinical and Behavioral Characteristics}

Half of the study participants $(199 ; 50.9 \%)$ had a CD4 count of less than 500 cells $/ \mathrm{mm}^{3}$. Less than one-fifth of the participants $(70 ; 17.9 \%)$ had viral load greater than or equal to 1000 copies $/ \mathrm{mL}$. Ninety-five percent of the study participants were classified as stage-one according to the WHO staging categories (Table 2).

\section{Magnitude of Overall Quality of Life}

The environmental health-related quality of life domain was reached by the highest percentage of participants (200; 51.2\%) among the six domains. The psychological domain ranked second $(195 ; 49.9 \%)$ and the social relationship domain ranked last $(173 ; 44.2 \%)$. Almost half of the participants had a poor overall QOL score (185; 47.1\%) (Figure 1).

\section{Multivariable Logistic Regression Analysis}

The multivariable logistic regression analysis was carried out to determine possible associations between the independent variables and quality of life. In the simple binary logistic regression, variables associated with quality of life (QOL) with a p-value $\leq 0.25$ were: wealth index, adherence status, duration on ART, substance abuse, recent CD4 
Table I Socio-Demographic Characteristics of the Study Participants at Public Health Facilities of Arba Minch Town, Gamo Zone, 2019 (N=39l)

\begin{tabular}{|c|c|c|}
\hline Variables & Categories & Frequency (Percent) \\
\hline \multirow[t]{5}{*}{ Age } & $15-24$ & $27(6.9)$ \\
\hline & $25-34$ & $107(27.4)$ \\
\hline & $35-44$ & $156(39.9)$ \\
\hline & $45-64$ & $93(23.8)$ \\
\hline & $\geq 65$ & $8(2.0)$ \\
\hline \multirow[t]{2}{*}{ Sex } & Male & $159(40.7)$ \\
\hline & Female & $232(59.3)$ \\
\hline \multirow[t]{5}{*}{ Ethnicity } & Gamo & $225(57.5)$ \\
\hline & Amhara & $54(13.8)$ \\
\hline & Wolayita & $48(12.3)$ \\
\hline & Gofa & $46(I I .8)$ \\
\hline & Others & $18(4.6)$ \\
\hline \multirow[t]{4}{*}{ Religion } & Orthodox & $238(60.9)$ \\
\hline & Protestant & $142(36.2)$ \\
\hline & Muslim & $10(2.6)$ \\
\hline & Catholic & $\mathrm{I}(0.3)$ \\
\hline \multirow[t]{4}{*}{ Marital status } & Single & $85(21.7)$ \\
\hline & Married & $145(37.2)$ \\
\hline & Divorced & $83(21.2)$ \\
\hline & Widowed & $78(19.9)$ \\
\hline \multirow[t]{4}{*}{ Education status } & Unable to read and write & $123(31.5)$ \\
\hline & Primary & $119(30.4)$ \\
\hline & Secondary & $106(27.1)$ \\
\hline & Diploma and above & $43(11.0)$ \\
\hline \multirow[t]{7}{*}{ Occupation } & Student & $18(4.6)$ \\
\hline & Gov't employee & $82(2 I)$ \\
\hline & Private employer & $149(38.1)$ \\
\hline & Farmer & $21(5.4)$ \\
\hline & House wife & $49(12.5)$ \\
\hline & Daily labor & $64(16.4)$ \\
\hline & Others & $8(2.0)$ \\
\hline \multirow[t]{2}{*}{ Residence } & Urban & $360(92.1)$ \\
\hline & Rural & $31(7.9)$ \\
\hline \multirow[t]{5}{*}{ Wealth Index } & Lowest & $76(19.6)$ \\
\hline & Second & $84(21.5)$ \\
\hline & Middle & $92(23.5)$ \\
\hline & Fourth & $60(15.3)$ \\
\hline & Highest & $79(20.2)$ \\
\hline
\end{tabular}

Notes: Keys =Others; Gurage, Oromo, Ari, Sidama.

count, nutritional status, depression, having social support, and perceived stigma. After adjusting for the above variables, factors that were statistically correlated with the outcome variables in multivariable binary logistic regression were: CD4 count, nutritional status, depression, social
Table 2 Clinical and Behavioral Characteristics of the Study Participants at Public Health Facilities of Arba Minch Town, Gamo Zone, 2019 (N=39I)

\begin{tabular}{|l|l|l|}
\hline Variable & Category & Frequency (Percent) \\
\hline Recent CD4 count & $\begin{array}{l}<500 \mathrm{cell} / \mathrm{mm}^{3} \\
\geq 500 \mathrm{cell} / \mathrm{mm}^{3}\end{array}$ & $\begin{array}{l}199(50.9) \\
192(49.1)\end{array}$ \\
\hline Viral load & $\begin{array}{l}<000 \mathrm{copies} / \mathrm{mL} \\
\geq 1000 \mathrm{copies} / \mathrm{mL}\end{array}$ & $\begin{array}{l}321(82.1) \\
70(17.9)\end{array}$ \\
\hline Current WHO stage & Stage I & $372(95.1)$ \\
& Stage 2 & $11(2.8)$ \\
& Stage 3 & $7(1.8)$ \\
\hline Stage 4 & $1(0.3)$ \\
\hline Nutritional status & Malnourished & $183(46.8)$ \\
& Normal & $208(53.2)$ \\
\hline Current TB status & Yes & $14(3.6)$ \\
& No & $377(96.4)$ \\
\hline Duration on ART & $<57$ month & $238(60.9)$ \\
& $\geq 57$ month & $153(39.1)$ \\
\hline Adherence status & Good adherence & $307(78.5)$ \\
& Poor adherence & $84(21.5)$ \\
\hline HIV disclosure status & Yes & $348(89.0)$ \\
& No & $43(11.0)$ \\
\hline Depression status & Yes & $204(52.2)$ \\
& No & $187(47.8)$ \\
\hline & Good & $203(51.9)$ \\
\hline & Poor & $212(54.2)$ \\
& Yes & $179(45.8)$ \\
\hline
\end{tabular}

support and perceived stigma. Participants who had recent CD4 count greater than or equal to $500 \mathrm{cell} / \mathrm{mm}^{3}$ were 1.96 times more likely to have good QOL than their counterparts with recent CD4 count $<500$ cell $/ \mathrm{mm}^{3}$ (AOR $=1.96,95 \% \mathrm{CI} ; 1.18-3.27)$. Participants who had normal nutrition status were 2.66 times more likely to have good QOL than their counterparts (AOR $=2.66,95 \%$ CI; 1.58-4.49). Participants who had no depression were 10.59 times more likely to have good QOL than those who had depression (AOR=10.59, 95\% CI; 6.16-18.21). Participants who had good social support were 6.18 times more likely to have good QOL than those who had no social support (AOR $=6.18,95 \% \mathrm{CI} ; 3.56-10.75)$. The odds ratio of having good QOL among participants without perceived stigma was 2.75 times higher than those participants who had perceived stigma ( $\mathrm{AOR}=2.75,95 \%$ CI; 1.62-4.67)(Table 3). 


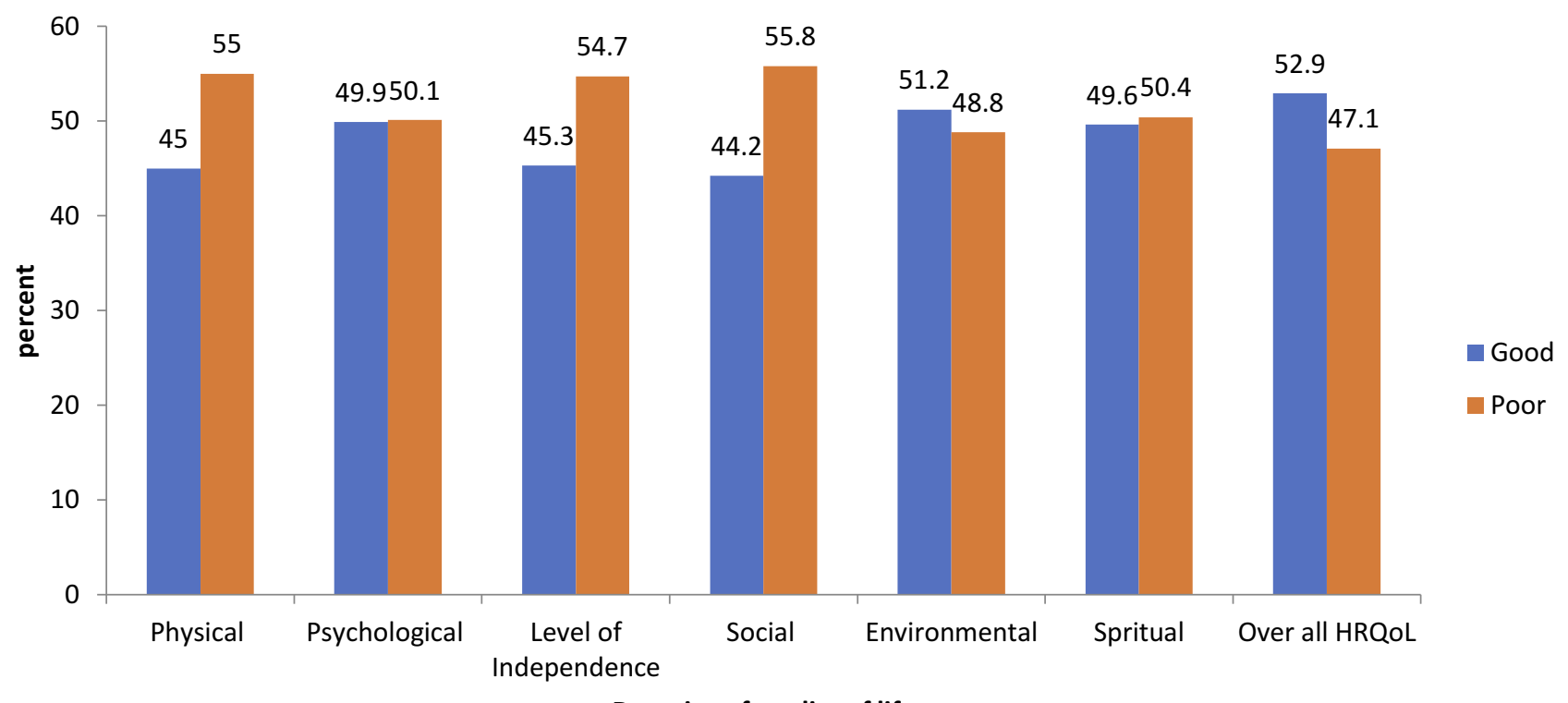

Domains of quality of life

Figure I Magnitude of quality of life dimensions among participants at public health facilities of Arba Minch town, Ethiopia, 2019 (N=39I).

Table 3 Factors Associated with Overall Quality of Life Among People Living with HIV Attending ART at Public Health Facilities of Arba Minch Town, South Ethiopia, $2019(\mathrm{~N}=319)$

\begin{tabular}{|c|c|c|c|c|c|c|}
\hline \multirow[t]{2}{*}{ Variables } & \multirow[t]{2}{*}{ Category } & \multicolumn{2}{|c|}{ Quality of Life } & \multirow[t]{2}{*}{ COR $(95 \% \mathrm{Cl})$} & \multirow[t]{2}{*}{ AOR(95\% Cl) } & \multirow[t]{2}{*}{ P-value } \\
\hline & & Good (\%) & Poor (\%) & & & \\
\hline Recent CD4 & $\begin{array}{l}<500 \mathrm{cell} / \mathrm{mm}^{3} \\
\geq 500 \mathrm{cell} / \mathrm{mm}^{3}\end{array}$ & $\begin{array}{l}87(42.0) \\
120(58.0)\end{array}$ & $\begin{array}{l}112(60.9) \\
72(39.1)\end{array}$ & $\begin{array}{l}\text { I } \\
2.15(1.43-3.22)\end{array}$ & $1.96(1.94-6.17)$ & 0.001 \\
\hline Nutritional status & $\begin{array}{l}\text { Malnutrition } \\
\text { Normal }\end{array}$ & $\begin{array}{l}81(39.1) \\
126(60.9)\end{array}$ & $\begin{array}{l}102(55.4) \\
82(44.6)\end{array}$ & $\begin{array}{l}\text { I } \\
1.94(1.29-2.90)\end{array}$ & $\begin{array}{l}\text { I } \\
2.66(1.18-3.27)\end{array}$ & 0.001 \\
\hline Depression status & $\begin{array}{l}\text { Yes } \\
\text { No }\end{array}$ & $\begin{array}{l}61(29.5) \\
146(70.5)\end{array}$ & $\begin{array}{l}\mid 43(77.7) \\
4 \mid(22.3)\end{array}$ & $\begin{array}{l}\text { I } \\
8.35(5.28-13.20)\end{array}$ & $\begin{array}{l}1 \\
10.59(6.16-18.21)\end{array}$ & 0.001 \\
\hline Social support & $\begin{array}{l}\text { Good } \\
\text { Poor }\end{array}$ & $\begin{array}{l}130(62.8) \\
77(44.4)\end{array}$ & $\begin{array}{l}58(31.5) \\
126(68.5)\end{array}$ & $\begin{array}{l}3.65(2.4 I-5.58) \\
I\end{array}$ & $\begin{array}{l}6.18(3.56-10.75) \\
1\end{array}$ & 0.001 \\
\hline Perceived stigma & $\begin{array}{l}\text { Yes } \\
\text { No }\end{array}$ & $\begin{array}{l}92(31.2) \\
115(55.6)\end{array}$ & $\begin{array}{l}120(65.2) \\
64(34.8)\end{array}$ & $\begin{array}{l}\text { I } \\
2.34(1.56-3.53)\end{array}$ & $\begin{array}{l}\text { I } \\
2.75(1.62-4.67)\end{array}$ & 0.001 \\
\hline
\end{tabular}

\section{Discussion}

This study assessed quality of life and factors associated with it among people living with HIV attending ART at public health facilities of Arba Minch town, Southern Ethiopia. The study showed that $52.9 \%(48.3 \%, 57.8 \%)$ of respondents had good status of overall QOL. The percentage of participants with good overall QOL in this study was slightly higher than the findings from similar studies conducted in Jimma town (46.5\%) and Felege Hiwot referral hospital (43.6\%). ${ }^{14,23}$ This difference may be due to socioeconomic differences in the study populations and the way the outcome variables were measured. However, the overall QOL in our study was lower than in similar studies conducted in Ghana, Burkina Faso, and Central India. ${ }^{12,13,24}$ Possible reasons might be due to variation in the sampling techniques and/or the sample sizes. This study showed that in our sample CD4 count, nutritional status, depression, social support and perceived stigma were factors associated with overall quality of life. Participants whose 
recent CD4 count greater than or equal to $500 \mathrm{cell} / \mathrm{mm}^{3}$ were twice as likely to have a good overall QOL than participants with CD4 count less than 500 cells $/ \mathrm{mm}^{3}$. This finding is consistent with the results of similar studies conducted in South Africa, Rwanda and Ireland. ${ }^{25-27}$ We suggest that the increased risk of PLWH being affected by many opportunistic infections as a result of having a low CD4 count and debilitated immunity, in turn eventually deteriorates their QOL. In contrast, the CD4 count of PLWH was not significantly associated with QOL in similar studies from India, Ireland, Vietnam and Rwanda. ${ }^{24,26-28}$ This could be due to differences in culture and health system factors, which can support healthrelated QOL of PLWH in these different settings independently of their CD4 count. Participants with normal nutritional status in this study were 3 times more likely to have good QOL than the malnourished group. This finding is in line with studies conducted in Western Ethiopia and South Africa. ${ }^{19,29}$ The possible explanation could be because better nutritional status promotes the body's ability to protect against infectious diseases, promote health and enable a productive lifestyle that enhances many aspects of QOL. Participants without depression were 9.4 times more likely to have a good overall QOL. This finding is consistent with studies conducted in North West Ethiopia, Addis Ababa, and Kathmandu Nepal. ${ }^{18,30,31}$ In addition to the intrinsic negative effect of depression on QOL, there may be secondary contributory factors such as the isolation and discrimination that depressed patients may experience, and lack of motivation may result in low adherence to treatment. Participants with good social support were 6 times more likely to have a good overall QOL. This result was similar to studies carried out in Ethiopia in Jimma town public health facilities, Shewa and Addis Ababa, and in Burkina Faso. $^{13,19,23,32}$ Patients with good social support inevitably experience a better QOL and also usually comply more fully with chronic care follow-up, which in turn further improves their health and hence their QOL. Having a good overall QOL was nearly 3 times higher among patients without perceived stigma, which is consistent with the results studies carried out in Ethiopia in Mekelle and Addis Ababa, and in Iran. ${ }^{3,32,33}$ Perceived stigma from the surrounding society contributes to loss of hope and depression; stigma from within the healthcare system could reduce adherence to chronic care follow-up.

Limitations of this study were: QOL in our participants was not compared to similar analysis of the same variables in HIV-negative people, so we were unable to distinguish between the effects of HIV-related and HIV-unrelated factors. Since the QOL questionnaire has some sensitive issues, social desirability bias might be induced. The measurement of QOL was not consistent across different literatures, therefore this study used researches conducted to measure healthrelated QOL and QOL interchangeably for comparison.

\section{Conclusion}

Nearly half of the adult PLWH receiving HAART at Arba Minch town had poor QOL. CD4 count, social support, depression and perceived stigma were associated with health-related QOL. PLWH should be encouraged to be part of social structures like mother's support group and associations of PLWH that support their social and psychological health. The health system should give attention to counseling on chronic care adherence and nutritional support to improve the clinical profiles of PLWH as well as their quality of life.

\section{Acknowledgments}

The research team highly acknowledges Arba Minch University, College of Medicine and Health Science for securing funding for this research. We are thankful for unreserved consent of the research participants. We thank the leaders at health facilities of Arba Minch town and Gamo Zone for their permission to proceed with this research work. Last, but not the least, we recognize Dr. Basiro Davey and Mr. Jean-Marc Mercy for their unreserved contribution in English language editing during manuscript preparation.

\section{Disclosure}

The authors report no conflicts of interest in this work.

\section{References}

1. UNAIDS. AIDSinfo; 2018. Available at: https://www.unaids.org/sites/ default/files/media_asset/unaids-data-2018_en.pdf. Accessed 21 April 2019.

2. Office FHAPaC. Analysis: HIV/AIDS is Surging in Ethiopia, Again; 2017. Available at: http://addisstandard.com/analysis-hivaids-is-sur ging-in-ethiopia-again/. Accessed 1 April 2019.

3. Tesfay A, Gebremariam A, Gerbaba M, Abrha H. Gender differences in health related quality of life among people living with HIV on highly active antiretroviral therapy in Mekelle Town, Northern Ethiopia. Biomed Res Int. 2015. doi:10.1155/2015/516369

4. Portillo CJ, Méndez MR, Holzemer W, Corless IB. Quality of life of ethnic minority persons living with HIV/AIDS. $J$ Multicultural Nurs Health. 2005;11(1):31-37.

5. Aranda-Naranjo B. Quality of life in the HIV-positive patient: implications and consequences. J Assoc Nurses AIDS Care. 2004;15(5):20S7S. doi: $10.1177 / 1055329004269183$

6. WHO. 1998. Development of the World Health Organization WHOQOL-BREF Quality of Life Assessment. The WHOQOL Group. Psychol Med. 
7. Cooper V, Clatworthy J, Harding R, Whetham J. Measuring quality of life among people living with HIV: a systematic review of reviews. Health Qual Life Outcomes. 2017;15(1):220. doi:10.1186/s12955-017-0778-6

8. Rüütel KPH, Loit HM, Uusküla A. Factors influencing quality of life of people living with HIV in Estonia: a cross-sectional survey. $J$ Int AIDS Soc. 2009;12:13. doi:10.1186/1758-2652-12-13

9. Basavaraj K, Navya M, Rashmi R. Quality of life in HIV/AIDS. Indian J Sex Transm Dis. 2010;31(2):75. doi:10.4103/02537184.74971

10. Mofolorunsho KC, Nwankwo EO, Babatunde T. Socio-economic factors influencing the quality of life of people living with HIV/ AIDS in Kogi, Nigeria. Nature Sci. 2013;11(8):33-39.

11. Mweemba P, Zeller R, Ludwick R, Gosnell D. Quality of life of zambians living with HIV \& AIDS. Med J Zambia. 2009;36 (4):143-150

12. Osei-Yeboah J, Owiredu WK, Norgbe GK, et al. Quality of life of people living with HIV/AIDS in the Ho Municipality, Ghana: a cross-sectional study. AIDS Res Treat. 2017;2017.

13. Bakiono F, Ouédraogo L, Sanou M, et al. Quality of life in people living with HIV: a cross-sectional study in Ouagadougou, Burkina Faso. SpringerOpen J. 2014;3(372):1-11.

14. Amare A, Aemiro Y, Amsalu F, Solomon M. Health related quality of life assessment and associated factors among people on highly active antiretroviral therapy at Felege Hiwot Referral Hospital, Bahir Dar, North West Ethiopia. J AIDS Clin Res. 2014;5:1.

15. Abebe Weldsilase Y, Likka MH, Wakayo T, Gerbaba M. Healthrelated quality of life and associated factors among women on antiretroviral therapy in health facilities of Jimma Town, Southwest Ethiopia. Adv Public Health. 2018.

16. Basavaraj KHNM, Rashmi R. QoL in HIV/AIDS. Indian J Sexual Transm Dis. 2010;3:2.

17. Oguntibeju OO. Quality of life of people living with HIV and AIDS and antiretroviral therapy. HIV/AIDS. 2012;4:117.

18. Timilsina SRK. Assessing quality of life and depression among people living with HIV/AIDS and TB-HIV coinfection in Kathmandu, Nepal. Saarc J Tuber Lung Dis HIV/AIDS. 2014;11:2.

19. Gebremichael DY, Hadush KT, Kebede EM, Zegeye RT. Gender difference in health related quality of life and associated factors among people living with HIV/AIDS attending antiretroviral therapy at public health facilities, western Ethiopia: comparative cross sectional study. BMC. 2018;18:537.

20. Deribew A, Tesfaye M, Hailmichael Y, et al. Tuberculosis and HIV co-infection: its impact on quality of life. BMC. 2009;7:105.

21. World Health Organization. Users' manual for scoring and coding WHOQOL-HIV instruments. Geneva, Switzerland: Department of Mental Health and Substance Dependence; 2002.
22. Erchafo BAT, Tsega G, Adamu A, et al. Are we too far from being client centered? PLoS One. 2018;13:10. doi:10.1371/journal. pone. 0205681

23. Abebe Weldsilase Y, Likka MH, Wakayo T, Gerbaba M. Healthrelated quality of life and associated factors among women on antiretroviral therapy in health facilities of Jimma Town, Southwest Ethiopia. Adv Public Health. 2018;2018.

24. Kumar A, Girish H, Nawaz AS, Balu P, Kumar BV. Determinants of quality of life among people living with HIV/AIDS: a cross sectional study in central Karnataka, India. Int J Med Sci Public Health. 2014;3 (11):125-128. doi:10.5455/ijmsph.2014.230820142

25. Andrew Tomita NG. Health-related quality of life dynamics of HIV-positive South African women up to ART initiation: evidence from the CAPRISA 002 acute infection cohort study. AIDS Behav. 2014;18(6):1114-1123. doi:10.1007/s10461-013-0682-y

26. Biraguma J, Mutimura E, Frantz JM. Health-related quality of life and associated factors in adults living with HIV in Rwanda. SAHARA-J. 2018;15(1):110-120． doi:10.1080/17290376.2018.152 0144

27. George S, Bergin C, Clarke S, Courtney G, Codd MB. Health-related quality of life and associated factors in people with HIV: an Irish cohort study. Health Qual Life Outcomes. 2016;14(1):115. doi:10.1186/s12955-016-0517-4

28. Tran BX. Quality of life outcomes of antiretroviral treatment for HIV/AIDS patients in Vietnam. PLoS One. 2012;7(7):e41062. doi:10.1371/journal.pone.0041062

29. Igumbor J, Stewart A, Holzemer W. Comparison of the health-related quality of life, CD4 count and viral load of AIDS patients and people with HIV who have been on treatment for 12 months in rural South Africa. SAHARA-J. 2013;10(1):25-31.

30. Mekuriaw Alemayehu MW, Mesfin N, Tamiru A, Gebayehu A. Health-related quality of life of HIV infected adults with and without visceral leishmaniasis in Northwest Ethiopia. Health Qual Life Outcomes. 2017;15:65.

31. Abera K, Gedif T, Engidawork E, Gebre-Mariam T. Quality of life of people living with HIV/AIDS and on highly active antiretroviral therapy in Ethiopia. Afr J AIDS Res. 2010;9(1):31-34. doi:10.2989/ 16085906.2010 .484560

32. Mekuria LA, Sprangers MA, Prins JM, Yalew AW, Nieuwkerk PT. Health-related quality of life of HIV-infected adults receiving combination antiretroviral therapy in Addis Ababa. AIDS Care. 2015;27 (8):934-945. doi:10.1080/09540121.2015.1020748

33. Charkhian A, Fekrazad H, Sajadi H, Rahgozar M, Abdolbaghi MH, Maddahi S. Relationship between health-related quality of life and social support in HIV-infected people in Tehran, Iran. Iran J Public Health. 2014;43(1):100.
HIV/AIDS - Research and Palliative Care

\section{Publish your work in this journal}

HIV/AIDS - Research and Palliative Care is an international, peerreviewed open-access journal focusing on advances in research in HIV, its clinical progression and management options including antiviral treatment, palliative care and public healthcare policies to control viral spread. The manuscript management system is completely online and includes a very quick and fair peer-review system, which is all easy to use. Visit http://www.dovepress.com/testimonials.php to read real quotes from published authors. 